\title{
Mechanical Properties of the Connectors of Steel Frame Embedded and Hung with the Intercalated Multi-Ribbed Composite Wall
}

\author{
Chao GONG ${ }^{\mathrm{a}}$, Mingming JIA ${ }^{\mathrm{b}, 1}$ and Xin LIU ${ }^{\mathrm{b}}$ \\ ${ }^{a}$ China Metallurgical Construction Research Institute Co., Ltd., Beijing, 100088, China \\ ${ }^{\mathrm{b}}$ School of Civil Engineering, Harbin Institute of Technology, Harbin 150090, China
}

\begin{abstract}
The multi-ribbed composite wall (MRCW) structure has the advantage of energy-saving, low weight, and adjustable stiffness. The partition, enclosure, and load-bearing capacity can be realized simultaneously. When the steel frame embedded and hung with the intercalated multi-ribbed composite wall (MRCW), the steel frame columns are avoided to expose in the air, so the durability and heat insulation performance of the structure can be improved. The steel frame is connected with the intercalated multi-ribbed composite wall (MRCW) by wet connection, and the mechanical property and the deformation mode of the multiribbed composite wall (MRCW) and steel frame are researched. The mechanical property of stud shear connectors is qualitatively and quantitatively analyzed, which is beneficial to improve the related design methods of structures.
\end{abstract}

Keywords. Multi-ribbed composite wall, finite element analysis, mechanical property, stub shear connector, hysteretic behavior

\section{Introduction}

Steel frames with MRCW are more and more widely used in engineering structures. When the bottom floor of the frame is bare and the upper floors are installed with $\mathrm{MRCW}$, if the section of the bottom beams and columns can meet the design requirements, the $\mathrm{MRCW}$ of the upper floors will present three levels of progressive failure [1]; When there are holes in the MRCW, the strain of the frame slab reinforcement near the hole will increase significantly, which will reduce the integrity and repair ability of the structure. Jia et al. [2] proposed two simplified modeling methods for Frame-Supported Multi-Ribbed Composite Wall Structure (FSMRCW) and calibrated related parameters with experiments. The force and deformation mechanism of the structure was analyzed, and the influence of the size and position of the opening hole in the composite wall on the performance of the structure was discussed. Based on the research [3], the compressive strength, cracking resistance, and elastic modulus of MRCW had a great influence on the seismic resistance of the structure.

The wall panel and the frame could be integrally connected. The inner side of the frame beam was bolted to connecting steel plates, and the steel plates were welded to

\footnotetext{
${ }^{1}$ Mingming Jia, Corresponding Author, School of Civil Engineering, Harbin Institute of Technology, Harbin 150090, Chinas; E-mail: jiamingming@hit.edu.cn.
} 
the wall to achieve a rigid connection. The structural performance can also meet the specification requirements [4]. Okazaki et al. [5] introduced three kinds of connection methods for external wall panels and the frame widely used in Japan. They tested the structure using ADR articulated connection and found that the interaction between the wall panels and the frame was very small. The ADR connection joint was in good stress condition and had not been damaged. Zoubek et al. [6] proposed a hammer-head strap slip type joint mainly used in the corners of wall panels. The hammer-head strap joints provided out-of-plane restraint to limit the wall panels from out-of-plane displacement. The embedded grooves were set in the wall to allow it to slip so that the interaction between the wall panel and the frame is reduced. Many scholars have focus on the energy absorption connectors, which can be used to improve the seismic performance of structures with the panel walls [7-10].

This paper takes the steel frame embedded and hung with the intercalated multiribbed composite wall (the $10 \mathrm{~mm}$ gap between the embedded part and the frame column is filled with mortar) as the research object. Based on the metal ductile damage model to simulate the possible fracture failure of the connecting member, the finite element model was established by ABAQUS. The mechanical characteristics of the connectors at the interface between the MRCW and the frame beams had been analyzed in detail. The research results can provide support for the improvement of structural design methods.

\section{Structural Model and Finite Element Model Establishment}

The height and span of the single-layer single-span steel frame are $3000 \mathrm{~mm}$ and $3100 \mathrm{~mm}$ respectively, as shown in figure 1 . According to the design principle of the strong column and weak beam, the columns are HW300 $\times 200 \times 8 \times 12$ and the beams are HW2 $00 \times 150 \times 6 \times 10$. The steel grade is Q235B. The beam-column joints and the column base are rigidly connected, and the stiffening ribs are arranged on the column base flange. The MRCW used in the benchmark model has a thickness of $355 \mathrm{~mm}$ and a height of $2800 \mathrm{~mm}$. The embedded part has a width of $2780 \mathrm{~mm}$. The MRCW is composed of a $200 \mathrm{~mm}$ concrete frame slab (composed of RC frame and inner foam concrete), a $75 \mathrm{~mm}$ outer thermal insulation benzene slab, an $80 \mathrm{~mm}$ concrete cover slab (outer $50 \mathrm{~mm}$ concrete slab and inner $30 \mathrm{~mm}$ concrete slab), and steel wire mesh. The concrete of the frame slab and cover slab is $\mathrm{C} 30$, and the longitudinal reinforcement and stirrups are HRB400. The steel wire mesh is made of Q235B steel wire with a diameter of $3 \mathrm{~mm}$, and the distance between the grids is $150 \mathrm{~mm}$.

All structural components adopted a three-dimensional linear reduction integral unit in the finite element analysis, named C3D8R unit. The steel mesh and steel wire mesh inside the wall were slender members, ignored their radial shear effect, and adopted a two-node three-dimensional truss element (T3D2 element).

\section{Mechanical Properties of Stud Connectors}

The connection of steel frame embedded and hung with intercalated MRCW is a statically indeterminate overall connection scheme when adopted the traditional wet connection method. The MRCW and the outer frame were combined into a whole to resist external loads. The shear resistance connector on the interface born not only the 
shear but also the tension and compression caused by the bending of the frame. The connector was in a multi-directional force state (tension-shear coupling or compression-shear coupling), and its mechanical properties may have a significant impact on the structural integrity. Therefore, it is necessary to analyze the overall mechanical property of the structure connected by shear resistance studs. The 4.6-grade shear resistance stud (length $80 \mathrm{~mm}$ ) is adopted in the structure, and the stud diameters are $16 \mathrm{~mm}, 13 \mathrm{~mm}$ and $10 \mathrm{~mm}$ respectively. The influence of the shear resistance stud area on the connection performance of the wall resisting the lateral force and the mechanical property of the structure is analyzed. The model information of the structure is shown in table 1.

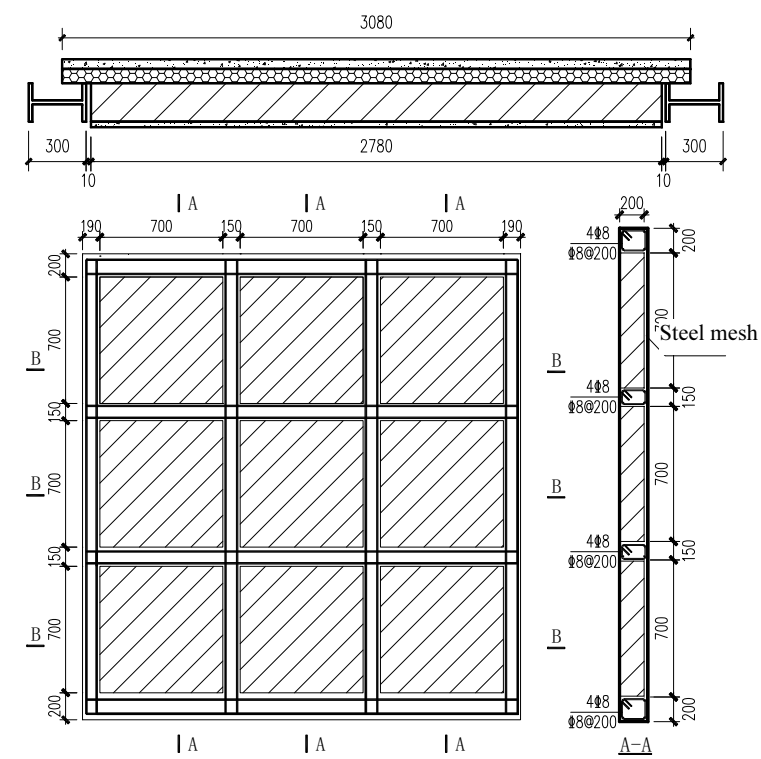

Figure 1. The steel frame embedded and hung with intercalated multi-ribbed composite wall.

Table 1. The model information of the structure

\begin{tabular}{llll}
\hline Specimen number & W325D16 & W325D13 & W325D10 \\
\hline Stud spacing & $325 \mathrm{~mm}$ & $325 \mathrm{~mm}$ & $325 \mathrm{~mm}$ \\
Stud diameter & $16 \mathrm{~mm}$ & $13 \mathrm{~mm}$ & $10 \mathrm{~mm}$ \\
Stud number & D16 & D13 & D10 \\
\hline
\end{tabular}

The simulation results show that the hysteresis curves of the three stud diameters are the same, as shown in figure 2. The low-strength material (foamed concrete) filled in MRCW is first damaged and destroyed when the structure is subjected to a horizontal load. A diagonal force zone appeared subsequently, shown a diagonal compression mode similar to the masonry infill wall without holes, as shown in figure 3. Eventually, the corner concrete of the MRCW embedded in the steel frame was broken. The damage of the foamed concrete and the outer cladding layer increased with the increase in height, and plastic hinges occurred in the beam-column joint area. In the overall diagonal force mode, the shear resistance studs are born less shear in the horizontal direction, and some studs had reached the plastic stage. The equivalent plastic strain (PEEQ) of the D13 shear resistance stud after loading with a $45 \mathrm{~mm}$ 
amplitude is approximately up to 0.034 , where D13 is the stud near the beam-column joint area. The maximum PEEQ of the D16 stud is up to 0.018. The D10 stud on the top yielded in a large area, the maximum PEEQ is up to 0.1, which is easy to low-cycle fatigue fracture under the cyclic load.

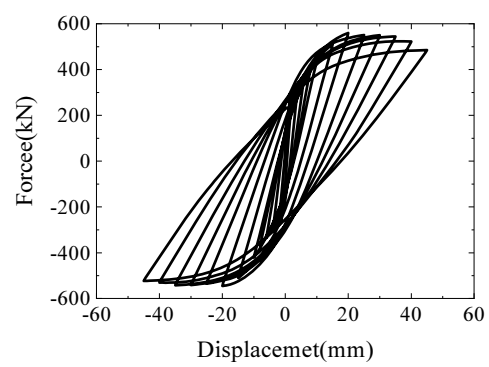

Figure 2. The hysteresis curve of the structure connecting the wall with bolts.

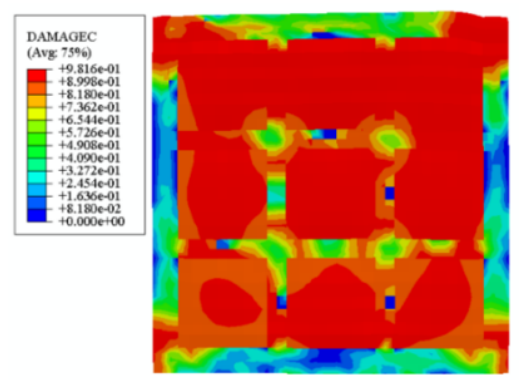

Figure 3. The $200 \mathrm{~mm}$ concrete frame slab compression damage cloud of the W325D13

When the stud diameter is small, plastic damage occurred on the edge studs, and the middle studs began to bear greater shear force than the edge studs as the lateral displacement increases, as shown in figure 4 . When the stud diameter increases, the plastic part of the outer studs and the damage decreased.

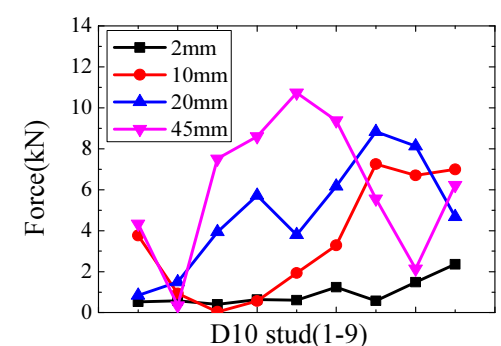

a) Shear (positive loading)

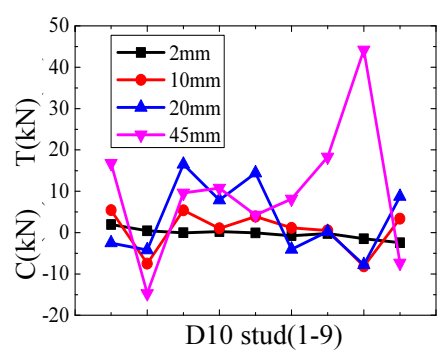

b) Tension and compression (positive loading)

Figure 4. Force of D10 stud on top beam in W325D10 model.

Although the studs that born the main interface shear force changed continually from the outside to the middle, the outside studs would not bear a small proportion of shear force due to serious damage in the later stage of loading, as shown in figure 5 and 
figure 6 . The rib beam was mainly flexural deformation along the span direction under the horizontal load, because the vertical stiffness of the rib column in the frame slab of the embedded part of the MRCW is higher than the stiffness of the foamed concrete, as shown in figure 7. It shows that the tension and compression of the studs changed significantly with the span. The rib column and the rib beam had the same flexural deformation characteristics. The corner concrete of the embedded part of the MRCW had obvious compression damage. The plastic hinge formed in the beam-column joint area of the outer frame, and the shear resistance studs on the interface yielded.

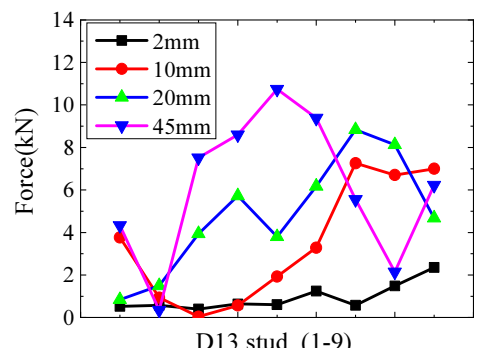

a) Shear

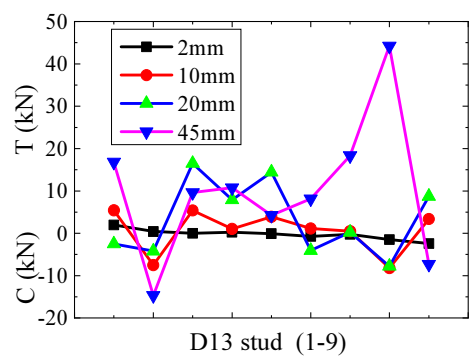

b) Tension and compression

Figure 5. Force of D13 stud on top beam in W325D13 model.

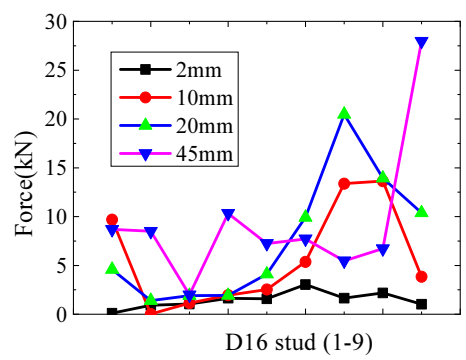

a) Shear

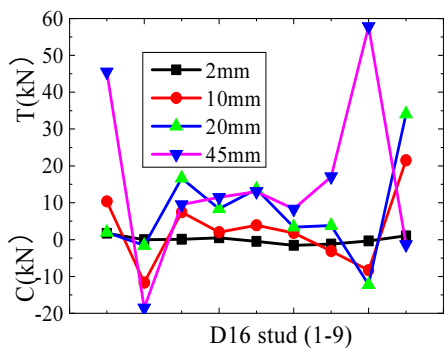

b) Tension and compression

Figure 6. Force of D16 stud on top beam in W325D16 model.

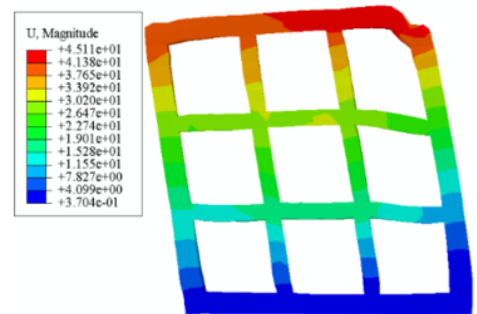

a) positive loading

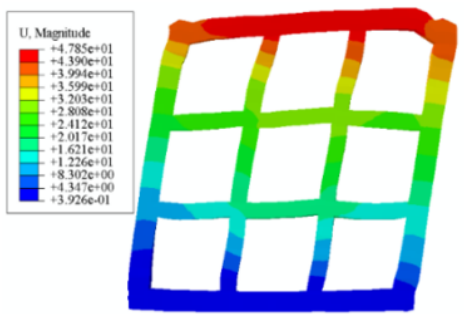

b) negative loading

Figure 7. Deformation of $200 \mathrm{~mm}$ concrete frame slab when W325D13 model is loaded with $45 \mathrm{~mm}$ (10 times magnification effect). 


\section{Conclusion}

The MRCW had a diagonal compression mode and a diagonal force zone in the loading plane. The concrete was mainly damaged on the diagonal force zone. The rib beam and column in the concrete frame slab are mainly flexural deformations along the span direction under the horizontal load. The shear, the tension, and the compression born by the stud shear connector gradually decreased from the outside to the inside. The degree of plasticity of the outer connector and the force on the inner shear connector increased with the increase of the loading displacement. The shear of the outer studs would be lower than the shear of the inner studs due to material damage and degradation when the stud diameter is small. The degree of non-linearity of the studs became lower as the stud diameter increases.

\section{Acknowledgments}

The support of Open Fund Project of Chinese National Steel Structure Engineering Technology Research Center (Grant No. YZB2017Ky01), the National Science Foundation of China through project (Grant No. 51978220).

\section{References}

[1] Jia SZ, Cao WL, Yuan Q, Zhang YC. Experimental study on frame-supported multi-ribbed composite walls under low-reversed cyclic loading. European Journal of Environmental and Civil Engineering. 2016 Mar; 20(3): 314-331.

[2] Jia SZ, Cao WL, Zhang YC, Yuan Q. Simplified calculation model and finite-element analysis of frame-supported ribbed-grid composite slab structure. KSCE Journal of Civil Engineering. 2018 Sep; 22(9): 3383-3394.

[3] Li B, Huang W, Luo B, Chen GX. Cycle behavior of precast composite wall with different ecological filled blocks. Advances in Structural Engineering. 2018 Jun; 22(2): 297-310.

[4] Li GC, Wang Y, Yang ZJ. Fang C. Shear behavior of novel T-stub connection between steel frames and precast reinforced concrete shear walls. International Journal of Steel Structures. 2018 Mar; 18(1): 115-126.

[5] Okazaki T, Nakashima M, Suita K, Matusmiya T. Interaction between the cladding and structural frame observed in a full-scale steel building test. Earthquake Engineering \& Structural Dynamics. 2007 Sep; 36: $35-53$.

[6] Zoubek B, Fischinger M, Isaković T. Cyclic response of hammer-head strap cladding-to-structure. Engineering Structures. 2016 Jul; 119: 135-148.

[7] Karadoğan F, Yüksel E, Khajehdehi A, et al. Cyclic behavior of reinforced concrete cladding panels connected with energy dissipative steel cushions. Engineering Structures, 2019 Jun; 189: 423-439.

[8] Lee CH, Kim J, Kim DH, et al. Numerical and experimental analysis of combined behavior of sheartype friction damper and non-uniform strip damper for multi-level seismic protection. Engineering Structures. 2016 May; 114: 75-92.

[9] Wang YH, Zhai XM, Wang W. Numerical studies of aluminum foam filled energy absorption connectors under quasi-static compression loading. Thin-Walled Structures. 2017 Jul; 116: 225-233.

[10] Wang YH, Liew JR, Lee SC, et al. Crushing of a novel energy absorption connector with curved plate and aluminum foam as energy absorber. Thin-Walled Structures. 2017 Feb; 111: 145-154. 